\title{
ANÁLISE DA SEGMENTAÇÃO ANATOMO-CIRÚRGICA ARTERIAL DO CÓLON DE COELHOS
}

\author{
PEDRO KASTEIN FARIA DA CUNHA BIANCHI ${ }^{1}$, JOSÉ ROBERTO KFOURY JUNIOR ${ }^{2}$, PATRÍ́CIA ORLANDINI \\ GONÇALEZ $^{3}$
}

\author{
${ }^{1}$ Pós-Graduando da Universidade de São Paulo, São Paulo, SP, Brasil. pedro.bianchi@usp.br \\ ${ }^{2}$ Professor Doutor da Universidade de São Paulo, São Paulo, SP, Brasil. \\ ${ }^{3}$ Professora Doutora da Universidade Moura Lacerda, Ribeirão Preto, SP, Brasil
}

RESUMO

\begin{abstract}
O conhecimento morfológico dos sistemas que compõem o corpo dos animais é fundamental para as áreas aplicadas da Medicina Veterinária. A descrição da distribuição dos vasos, nervos e ductos de um órgão subdivide-o em segmentos anátomo-cirúrgicos, os quais são importantes para a prática clínica e cirúrgica, tornando seus estudos relevantes em espécies de criação e experimentação. Desta forma, objetivou-se analisar a morfologia dos segmentos anátomo-cirúrgicos arteriais do cólon de coelhos, a fim de fornecer subsídios para a área aplicada, já que o cólon tem grande importância nesta espécie, por se tratar de uma representativa área de absorção de nutrientes. Para tanto, foram utilizados oito cadáveres de coelhos adultos (machos e fêmeas) injetados, via aorta torácica, com látex corado
\end{abstract}

(pigmento vermelho) para a marcação arterial e fixados em solução aquosa de formol a 10\%. A dissecação foi realizada a partir do ponto de origem das artérias que irrigam o cólon, sendo conduzida até a distribuição dos ramos na sua parede, observando-se a região e a associação de distribuição. Desta forma, pode-se verificar que o cólon recebe ramos provenientes das artérias mesentérica cranial e mesentérica caudal. Os ramos cólicos apresentam-se de forma metamérica e realizam anastomoses em toda sua extensão, o que dificulta a caracterização de um padrão segmentar. Porém, os ramos da artéria mesentérica caudal, destinados à parte final do cólon descendente, não apresentaram anastomoses aparentes com outros ramos.

PALAVRAS-CHAVE: anastomose, artérias, intestino, Orictolagus cuniculus. .

\section{ANALYSIS OF ANATOMICAL AND SURGICAL ARTERIAL SEGMENTATION IN THE COLON OF RABBITS}

\section{ABSTRACT}

The morphology and physiology of body systems is crucial to the applied areas of veterinary medicine. The description of the vessels, nerves and ducts distribution of an organ subdivided into anatomical and surgical segments are necessary for clinical and surgical practices, being relevant for the study of species breeding and experimentation. Thus, the aim of this study was to analyze the morphology of anatomical and surgical arterial segments in the colon of rabbits, because the colon has a great importance in this specie and it is a representative area of nutrient uptake.
Therefore, eight adult (male and female) rabbits were injected via the thoracic aorta with colored latex (red pigment) and fixed in aqueous $10 \%$ formaldehyde. The dissection was performed from the point of origin of arteries supplying the colon and the branches distribution and their associations were analyzed in the region. Thus, we could observe that the colon receives branches from the cranial and caudal mesenteric arteries. Colic branches are metameric and perform anastomoses in all their extension, which complicates the characterization of a standard 
segmentation. However, the branches of the caudal mesenteric artery, for the final part of the descending colon, showed no apparent anastomoses with other branches.

KEYWORDS: anastomosis; arteries; intestine; Orictolagus cuniculus.

\section{INTRODUÇÃO}

A segmentação representa um ramo da anatomia descritiva que estuda a distribuição dos vasos, ductos e nervos no parênquima de um órgão ${ }^{1}$. Nota-se uma descrição bastante detalhada, envolvendo, principalmente, a morfologia dos órgãos e sistemas orgânicos dos animais domésticos ${ }^{2,3}$; no entanto, informações sobre a distribuição vascular e nervosa são bastante escassas, não havendo, desse modo, um padrão segmentar para a correta caracterização dos grupos (carnívoros, herbívoros, ruminantes e herbívoros não ruminantes).

Com o mapeamento da distribuição dos vasos, nervos e ductos de um órgão, torna-se possível subdividi-lo em segmentos anátomocirúrgicos, os quais são importantes para a prática clínica e, principalmente, cirúrgica, o que torna relevante o estudo dos segmentos arteriais orgânicos em animais de experimentação, como os coelhos, muito utilizados como cobaias no desenvolvimento de novas técnicas cirúrgicas ${ }^{1}$.

Sabe-se que os órgãos ocos, como esôfago, estômago e intestino, têm seus segmentos pouco descritos nos animais, sendo possível encontrar informações sobre as variações da origem e distribuição das artérias destinadas aos mesmos ${ }^{4-6}$. Tratadistas clássicos como Getty ${ }^{2}$ e Dyce ${ }^{3}$ relatam apenas que o suprimento sanguíneo arterial do intestino é realizado pelas artérias mesentéricas cranial e caudal, que originam ramos para os respectivos segmentos intestinais. Contudo, são relatadas poucas descrições sobre a anatomia específica do colón de coelhos, especialmente informações relacionadas à distribuição arterial neste órgão, sendo que a maioria dos achados disponíveis são de caráter comparativo com o grupo dos herbívoros de ceco funcional ${ }^{7}$, focando, principalmente, na compreensão da fisiologia do órgão nos seus diferentes segmentos ${ }^{8}$.

Nesse contexto, torna-se importante a análise sobre o comportamento da distribuição das artérias destinadas ao intestino nos animais desta espécie, em especial o cólon, que representa uma importante área de absorção de nutrientes.

\section{MATERIAL E MÉTODOS}

Para a realização deste experimento, após a aprovação dos procedimentos preconizados pelo Comitê de Ética no Uso de Animais (protocolo $\mathrm{N}^{\circ}$ 02854-3) da Universidade Camilo Castelo Branco (UNICASTELO- Campus Descalvado), foram utilizados oito cadáveres de coelhos, sem padrão racial definido, adultos, machos e fêmeas provenientes de doações de criadores da região de Descalvado-SP.

Para a delimitação dos vasos arteriais, o sistema circulatório foi previamente preparado por meio de lavagem com solução aquosa de $\mathrm{NaCl}$ $0,9 \%$. Após a lavagem do sistema circulatório, foi injetado, via artéria aorta torácica, uma solução aquosa de Neopreme Látex $60 \%$ corado com pigmento específico (vermelho). Após a injeção de látex, as peças foram fixadas em solução aquosa de formol a $10 \%$ e mantidas submersas nesta mesma solução, por um período mínimo de 48 horas antes da dissecação.

A dissecação foi realizada a partir do ponto de origem das artérias que irrigam o cólon, observando-se variações nesta irrigação, e conduzida até a distribuição dos ramos na parede do órgão, observando-se a região e a associação de distribuição. Os segmentos intestinais cólicos descritos na literatura ${ }^{9}$ foram caracterizados, de acordo com a sua distribuição regional, e mensurados. As observações foram transcritas para fichas esquemáticas individuais, que permitiam o registro da distribuição de acordo com o território do órgão. Os resultados foram confrontados com a literatura, buscando-se sugestões de características morfo-funcionais e comparativas da espécie.

\section{RESULTADOS}

O cólon dos coelhos domésticos apresentou-se como o segmento intestinal mais desenvolvido proporcionalmente nas peças dissecadas. Seu suprimento arterial é realizado pelas artérias mesentéricas cranial, íleo-cólica, cólica proximal (direita), cólica média, mesentérica caudal e artéria cólica distal (esquerda) (Figura 1). 


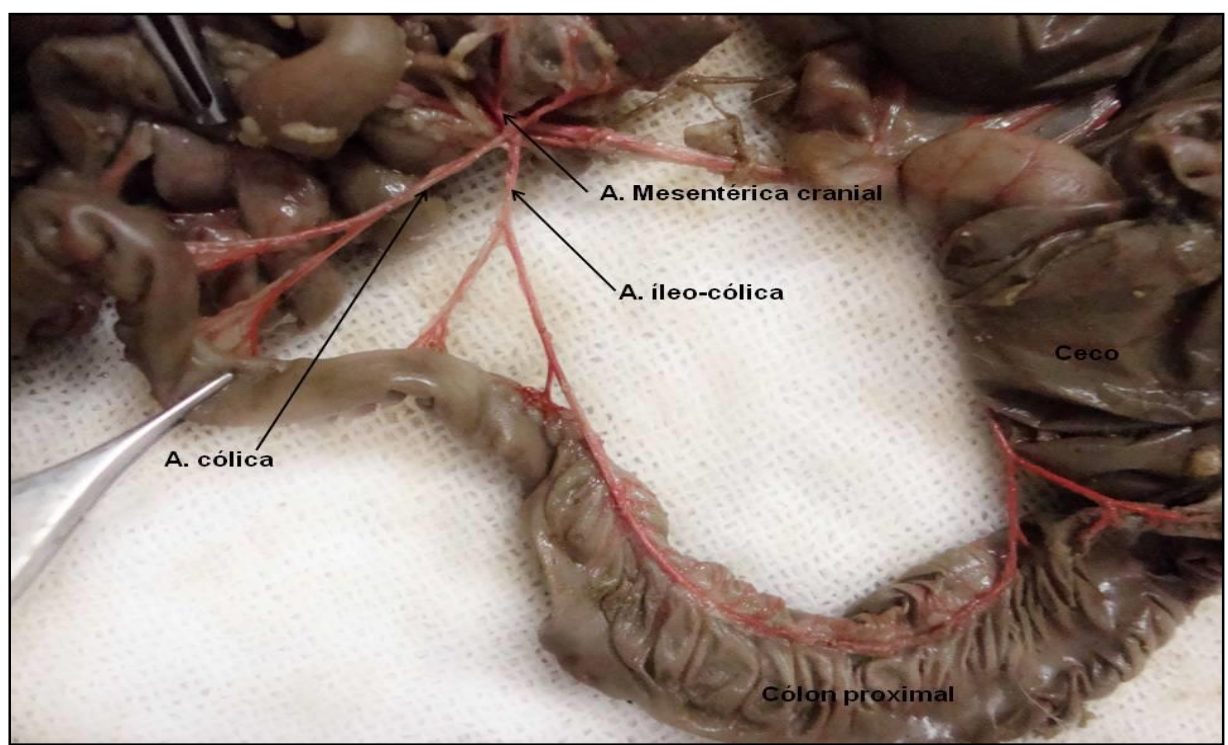

Figura 1: Origem das artérias destinas ao cólon de coelhos.

Quanto aos segmentos do cólon, foram identificados o cólon proximal, a flexura cólica e o cólon distal ${ }^{9}$. De acordo com os achados desta pesquisa, o cólon proximal apresentou uma variação de comprimento de 25,7 a $42,5 \mathrm{~cm}$, com um valor médio de $33,33 \mathrm{~cm}$. A flexura cólica representou o segmento médio, com um tamanho médio de $5,26 \mathrm{~cm}$, e extremos de 3,6 e $7,5 \mathrm{~cm}$. O cólon distal obteve como mensurações mínimas e máximas os valores 40,8 e 73,5 cm, com média de $59,33 \mathrm{~cm}$, sendo a maior porção do intestino ${ }^{10}$.

$\mathrm{O}$ cólon proximal recebeu suprimento sanguíneo da artéria íleo-cólica, fornecendo dois ramos em um animal, três ramos em quatro animais e quatro ramos em três animais. Os ramos secundários destinados ao segmento foram contados e apresentaram um número médio de 143, com mínimo de 49 e máximo de 244.
A flexura cólica recebeu ramos da artéria íleocólica, com um número de ramos médios de $22 \mathrm{e}$ extremos de três e 38 .

O cólon distal recebeu suprimento sanguíneo arterial das artérias cólica média e cólica esquerda. A artéria cólica média forneceu ramos em sete animais, sendo um ramo em um animal e dois ramos em seis animais. O número de ramos secundários variou de 71 a 129, com média de 83.

A artéria cólica esquerda forneceu um ramo para a porção distal do cólon proximal em todos os animais, com variação de 16 a 74 ramos secundários e média de 33 ramos.

Os ramos da artéria cólica esquerda, destinados aos segmentos, comunicaram-se (anastomose) (Figura 2), tornando os parâmetros de contagem restritos.

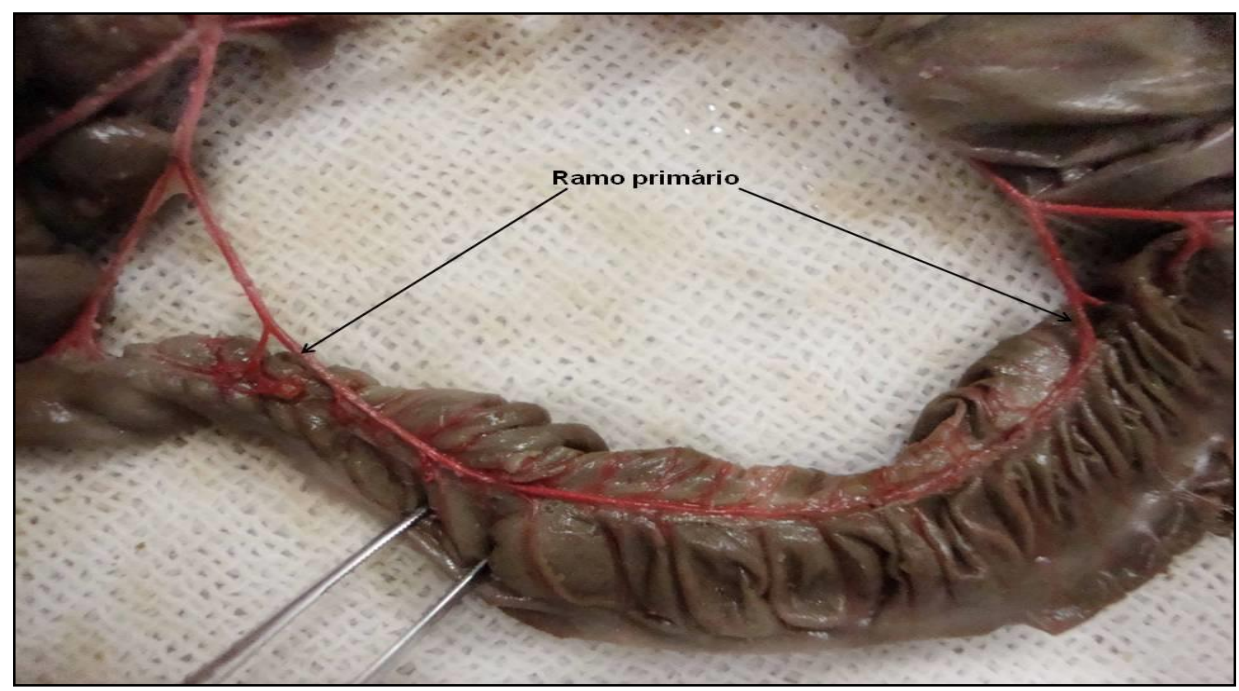

Figura 2: Anastomose entre ramos primários destinados ao cólon proximal. 


\section{DISCUSSÃO}

O intestino dos coelhos, de uma maneira geral, é bastante desenvolvido longitudinalmente, relacionando bem a função com a fisiologia do órgão. São herbívoros não ruminantes e sua alimentação baseia-se em alimentos fibrosos; portanto, o seu intestino é capaz de digerir a celulose, exclusivamente no ceco $^{7}$. Fisiologicamente, os alimentos que possuem celulose são bastante volumosos com digestão lenta, necessitando, dessa forma, de um espaço físico maior, para que o processo digestivo aconteça corretamente, sugerindo uma explicação para o tamanho do intestino $\operatorname{grosso}^{10}$.

Não foi visto, na dissecação dos intestinos dos coelhos, um padrão de segmentação arterial, existindo significativas variações nas ramificações arteriais destinadas ao cólon, que é um órgão oco ${ }^{4-6}$. Porém, foi possível perceber um caráter metamérico de distribuição arterial (Figura3), o que possibilitaria aplicações práticas que considerem o eixo longitudinal do órgão como parâmetro de referência.

Observou-se, em todas as peças dissecadas, a origem do suprimento arterial do intestino com ênfase na região do cólon, onde a irrigação arterial é proveniente da artéria mesentérica cranial e caudal, estando de acordo com Getty ${ }^{2}$ e Dyce ${ }^{3}$, sendo possível identificar o cólon proximal, a flexura cólica e o cólon distal, conforme sugerido na literatura por Quirilo et al. ${ }^{9}$.

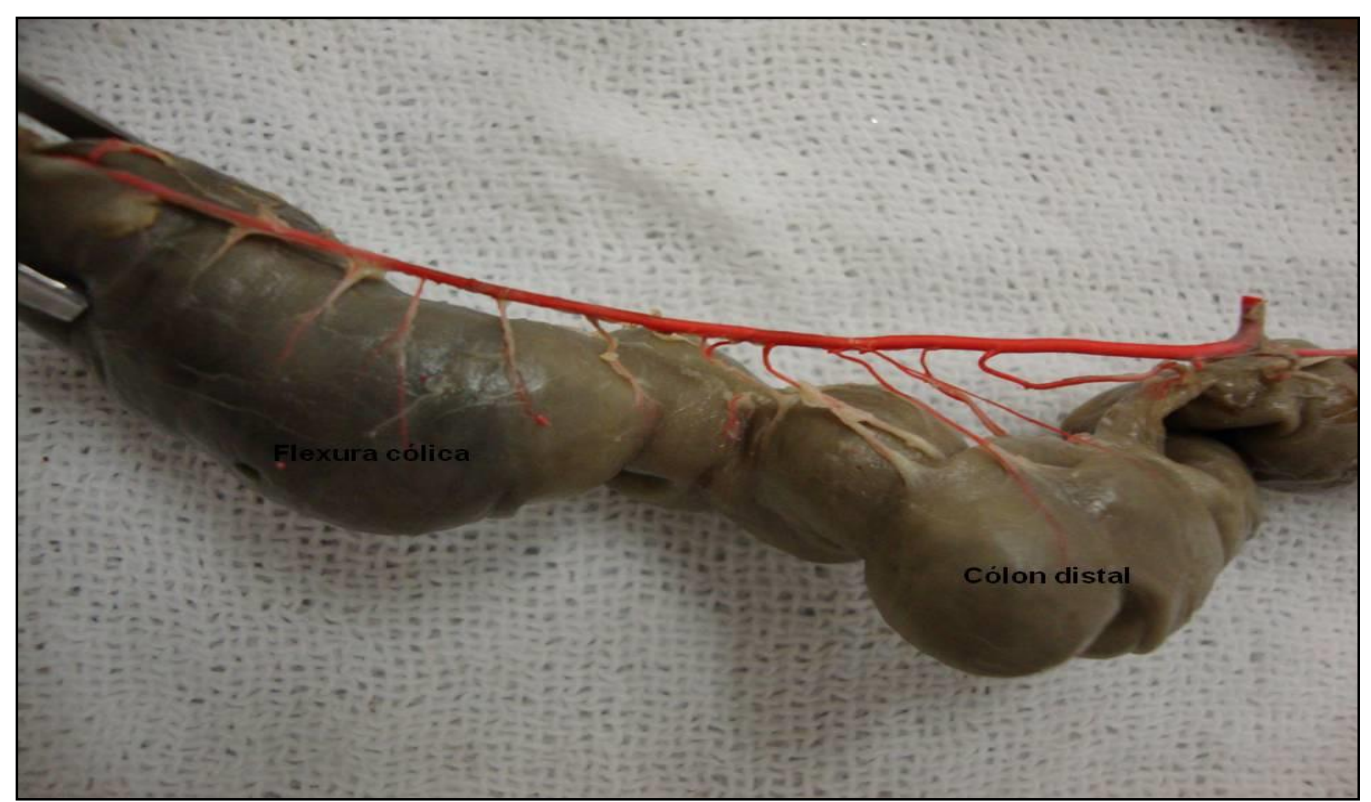

Figura 3: Padrão arterial metamérico observado nos segmentos cólicos de coelho.

A artéria íleo-cólica é responsável pelo suprimento do cólon proximal e da flexura cólica, bem como as artérias cólica média e distal pela vascularização do cólon distal. Todos os ramos se anastomosam, o que descaracteriza um padrão segmentar macroscópico, sendo possível estabelecer somente uma referência metamérica. No entanto, com as variações na distribuição arterial encontradas no cólon, sugere-se que as diferentes regiões do órgão podem apresentar funções fisiológicas diferenciadas ${ }^{8}$.

Nesse contexto, como a distribuição arterial não possui um padrão segmentar macroscópico característico, torna-se necessária a formulação de uma investigação microscópica e de outros estudos relacionados, como sugere Di Dio ${ }^{1}$, para a conclusão da formação não padronizada.

\section{CONCLUSÃO}

Nos animais utilizados para o desenvolvimento deste trabalho, o cólon apresentouse como o maior segmento intestinal e pode-se notar que o seu suprimento arterial é realizado pelas artérias mesentéricas cranial, íleo-cólica, cólica proximal (direita), cólica média, mesentérica caudal e pela cólica distal (esquerda).

Considerando o padrão segmentar, foi visto que a distribuição das artérias no órgão estudado não seguiu um padrão, dificultando a identificação e comparação das ramificações arteriais entre os animais. 


\section{REFERÊNCIAS}

1. Di Dio, J.A. Tratado de anatomia sistêmica aplicada. 2 ed. São Paulo: Atheneu; 2002.

2. Souza A.L.R., Resende L.C., Mortoza A.M., Ferreira J.R. Modelo de suprimento sanguíneo do intestino grosso do tamanduá bandeira (Myrmecophaga tridactyla). Ciência Rural [Internet]. 2010; [citado em 2014, maio, 10]; 40(3): 541-547. Disponível em http://dx.doi.org/10.1590/S010384782010005000027

3. Cavalcanti E.M. A vascularização arterial do cólon terminal (anatomia cirúrgica da artéria mesentérica inferior). Revista Brasileira de Coloproctologia. 1997; 17: $126-141$.

4. Machado M.R., Miglino M.A., Cabral V.P., Araújo N. Origem das artérias celíaca e mesentérica cranial em bubalinos (Bubalus bubalis, L. 1758). Brazilian Journal of Veterinary Research and Animal Science. 2000; 37: 89-95.

5. Gonçalez, P.O., Silva, F.O.C., Severino, R.S., Drummond, S.S. Origens e ramificações da artéria celíaca em fetos de suínos (Sus scrofa domesticus - Linnaeus, 1758) da linhagem Rezende. Bioscience Journal. 2003; 19: 83-91.
6. Gonçalez, P.O., Silva, F.O.C., Severino, R.S., Drummond, S.S. Origem e distribuição da artéria celíaca em fetos de suínos da raça Pietrain. Veterinária Notícias. 2004; 10: 19-16.

7. Barroso, D. C; Lima, A. M; Alonso,, L. S; Figueiredo, M. A. Comprimento total e relativo dos diferentes segmentos do intestino de coelhos nova zelândia. Arquivo Ciência. Veterinária Zoologia. .2007; 10: 101-104.

8. Snipes, R.L., Clauss, W., Weber, A., Hornicke, H. Structural and functional differences in various divisions of the rabbit colon. Cell and Tissue Research. 1982; 225: 331346.

9. Quirilo, M. A., Cabral, V.P., Simonelli S. Avaliação morfométrica dos intestinos de coelhos domésticos da raça Nova Zelândia. Iniciação Científica CESUMAR [Internet]. 2006; [citado em 2014 maio 8]; 8(1): 75-81. Disonível em http://www.cesumar.br/pesquisa/periodicos/index.php/icce sumar/article/view/127/65.

10. Amorim M.J.A., Silva Júnior V.A., Villarouco, F.M.O., Henrique, V.V.A. Longitud total del intestino de conejos sin raza definida (Oryctolagus cuniculus). Revista Chilena de Anatomia. 2002; 20:181-183.

Protocolado em: 29 maio 2013 Aceito em: 24 jan. 2014 